\title{
Nerve fibers in the tumor microenvironment in neurotropic cancer-pancreatic cancer and cholangiocarcinoma
}

\author{
Xiuxiang Tan $\mathbb{1}^{1,2,3} \cdot$ Shivan Sivakumar ${ }^{4,5} \cdot$ Jan Bednarsch $^{2} \cdot$ Georg Wiltberger $^{2}$ - Jakob Nikolas Kather ${ }^{6}$. \\ Jan Niehues ${ }^{6}$. Judith de Vos-Geelen $\mathbb{1}^{7} \cdot$ Liselot Valkenburg-van lersel $^{7} \cdot$ Svetlana Kintsler $^{8}$ - Anjali Roeth ${ }^{2,3}$. \\ Guangshan $\mathrm{Hao}^{9} \cdot$ Sven Lang ${ }^{2}$. Mariëlle E. Coolsen ${ }^{1} \cdot$ Marcel den Dulk $\mathbb{D}^{1,2} \cdot$ Merel R. Aberle $\mathbb{D}^{3} \cdot$ Jarne Koolen $\mathbb{D}^{1}$. \\ Nadine T. Gaisa $\mathbb{1}^{8} \cdot$ Steven W. M. Olde Damink ${ }^{1,2,3} \cdot$ Ulf P. Neumann ${ }^{1,2} \cdot$ Lara R. Heij $\mathbb{D}^{1,2,8}$
}

Received: 20 August 2020 / Revised: 6 November 2020 / Accepted: 18 November 2020 / Published online: 7 December 2020

(c) The Author(s) 2020. This article is published with open access

\begin{abstract}
Pancreatic ductal adenocarcinoma (PDAC) and cholangiocarcinoma (CCA) are both deadly cancers and they share many biological features besides their close anatomical location. One of the main histological features is neurotropism, which results in frequent perineural invasion. The underlying mechanism of cancer cells favoring growth by and through the nerve fibers is not fully understood. In this review, we provide knowledge of these cancers with frequent perineural invasion. We discuss nerve fiber crosstalk with the main different components of the tumor microenvironment (TME), the immune cells, and the fibroblasts. Also, we discuss the crosstalk between the nerve fibers and the cancer. We highlight the shared signaling pathways of the mechanisms behind perineural invasion in PDAC and CCA. Hereby we have focussed on signaling neurotransmitters and neuropeptides which may be a target for future therapies. Furthermore, we have summarized retrospective results of the previous literature about nerve fibers in PDAC and CCA patients. We provide our point of view in the potential for nerve fibers to be used as powerful biomarker for prognosis, as a tool to stratify patients for therapy or as a target in a (combination) therapy. Taking the presence of nerves into account can potentially change the field of personalized care in these neurotropic cancers.
\end{abstract}

\section{Introduction}

Pancreatic ductal adenocarcinoma (PDAC) and cholangiocarcinoma (CCA) are aggressive cancers with only a limited response to chemotherapy. PDAC mortality is estimated to exceed the total breast, prostate, and colorectal cancer deaths and be the second leading cancer-related death by

Lara R. Heij

lheij@ukaachen.de

1 Department of Surgery, Maastricht University Medical Centre, Maastricht, The Netherlands

2 Department of General, Gastrointestinal, Hepatobiliary and Transplant Surgery, RWTH Aachen University Hospital, Aachen, Germany

3 NUTRIM School of Nutrition and Translational Research in Metabolism, Maastricht University, Maastricht, The Netherlands

4 Department of Oncology, University of Oxford, Oxford, UK

5 Kennedy Institute of Rheumatology, University of Oxford, Oxford, UK
2030 [1, 2]. PDAC and CCA share many clinical characteristics, which include high mortality rates and low treatment efficacy [3]. Unfortunately, survival rates have not improved even from recent novel therapeutic targets such as immune checkpoints [3-7]. Biologically PDAC and CCA are characterized by desmoplastic stroma and this stromal compartment is thought to be held responsible for

6 Department of Medicine III, University Hospital RWTH Aachen, Aachen, Germany

7 Division of Medical Oncology, Department of Internal Medicine, GROW School for Oncology and Development Biology, Maastricht University Medical Center, Maastricht, The Netherlands

8 Institute of Pathology, University Hospital RWTH Aachen, Aachen, Germany

9 Translational Neurosurgery and Neurobiology, University Hospital RWTH Aachen, Aachen, Germany 
Fig. 1 Histology of perineural invasion in neurotropic cancer. Histology slide of PDAC (a) and CCA (b) in Hematoxylin and Eosin (H\&E) showing PNI, which is one of the shared pathological characteristics of both cancers. a PDAC slide with extended PNI and an almost identical histomorphology as CCA. b CCA with tumor cells massively invading the perineural space, surrounded by desmoplastic stroma and few small tumor glands in the stroma. a

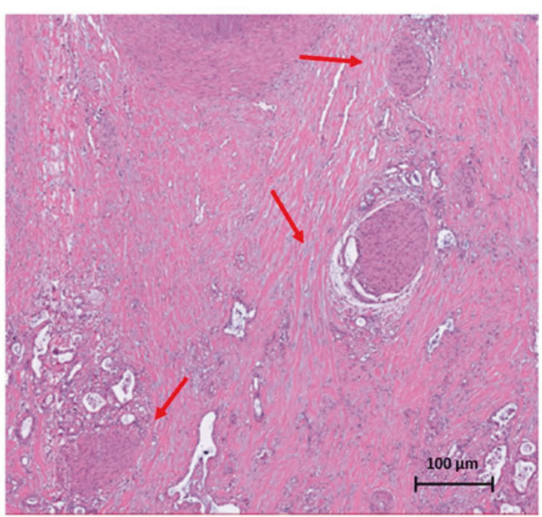

b

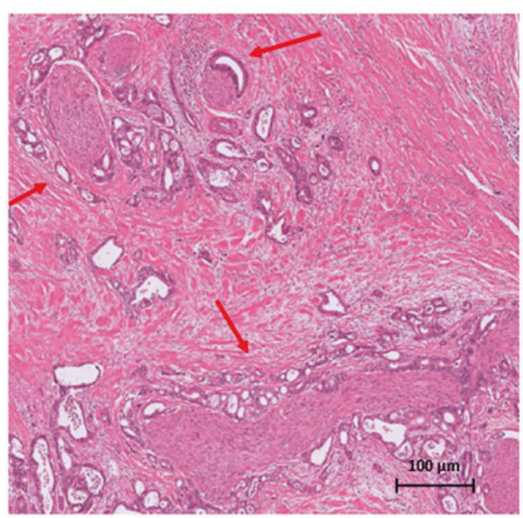

the poor efficacy of chemotherapy. Today, surgery combined with chemotherapy is the only chance of cure [8].

The tumor microenvironment (TME) is a fervent area of research interest as it contains a host of nonmalignant cells that play an important role in carcinogenesis such as fibroblasts, immune cells, blood- and lymphatic vessels, and nerve fibers. In this review, we will focus on the pathways involved in neurogenesis and the interaction between nerve fibers and the other components of the TME.

Internal organs are innervated by the autonomic nervous system (ANS), which is composed of two components: the sympathetic nervous system (SNS) and the parasympathetic nervous system (PSNS). Increasing evidence shows that not only the internal organs are innervated by the PSNS, but solid tumors also depend on the development of nerves in the TME for growth and invasion in adjacent tissue [9-11].

Besides the aggressive behavior and poor response to treatment, another shared feature of these two cancer types is perineural invasion (PNI), which is defined as cancer cells surrounding at least $33 \%$ of the epineurial, perineural, and endoneurial space of the nerve sheath [12]. PNI describes the process of cancer cells invading the nerve, crossing all layers of the nerve sheath. Once the cancer cells are invaded in the nerve, they have reached a favorable environment to travel intraneural and contribute to the progression of the disease. Over time different definitions for PNI have been used. It has been described as cancer cells located in the endoneurium associated with the Schwann cells [13] or later on as the presence of cancer cells along one of the layers of the nerve sheath [12, 14-16]. For pathologists invasion in one of these nerve sheath layers is used to report PNI and often a mixture of invasion in different layers is seen in one histological slide. Intraneural invasion in PDAC has been associated with higher frequency of local/distant recurrence when compared to cases with PNI but without intraneural invasion [17]. This provides some evidence that defining the level of PNI matters clinically but up to now this is not recommended in the guidelines for the pathologists. The exact underlying mechanism of PNI remains unknown $[12,18]$. A hypothesis is that the nerve fibers choose the path of "least resistance" and the cancer cells move along this low resistance path $[14,15]$. A recent insight showed that PNI was activating signaling pathways when cancer cells attacked the perineural spaces of the surrounding nerves [12]. Even though PNI commonly occurs in many solid tumors [19-22], PDAC and CCA are "neurotropic cancers" and have a high frequency of PNI [23]. It has been reported that almost all PDAC lesions contain PNI and about $75 \%$ of CCA lesions showed PNI [23-25] (Fig. 1 presents the classical PNI pathological characteristics of PDAC and CCA).

A novel biological phenomenon is the cancer-related neurogenesis, which is described in prostate cancer. The nerve fiber density is increased in paraneoplastic and neoplastic prostate lesions [26]. It is not known whether this cancer-related neurogenesis also occurs in PDAC or CCA. Exploring the role of alterations in nerve fibers in PDAC and CCA has the potential to be of importance in developing personalized medicine and finding an effective novel treatment strategy.

In this review, we aim to provide an overview of the current knowledge about nerve fiber crosstalk with cancer, and other components of the TME in PDAC and CCA.

\section{Innervation and neurotransmitters}

There is a complex nerve fiber network distributed around the pancreas, retroperitoneum and the biliary tree. Nerve fibers in the PDAC TME include axons originating from the sympathetic, parasympathetic, enteropancreatic or hepatic plexus, afferent nerve fibers and newly developed nerve fibers [27]. The nerve fibers of the SNS are derived from the lateral horn of the spinal cord whilst PSNS fibers originate from the brainstem (Fig. 2) [28-31]. A rich nerve network facilitates peripheral nerve invasion by cancer cells. Direct 


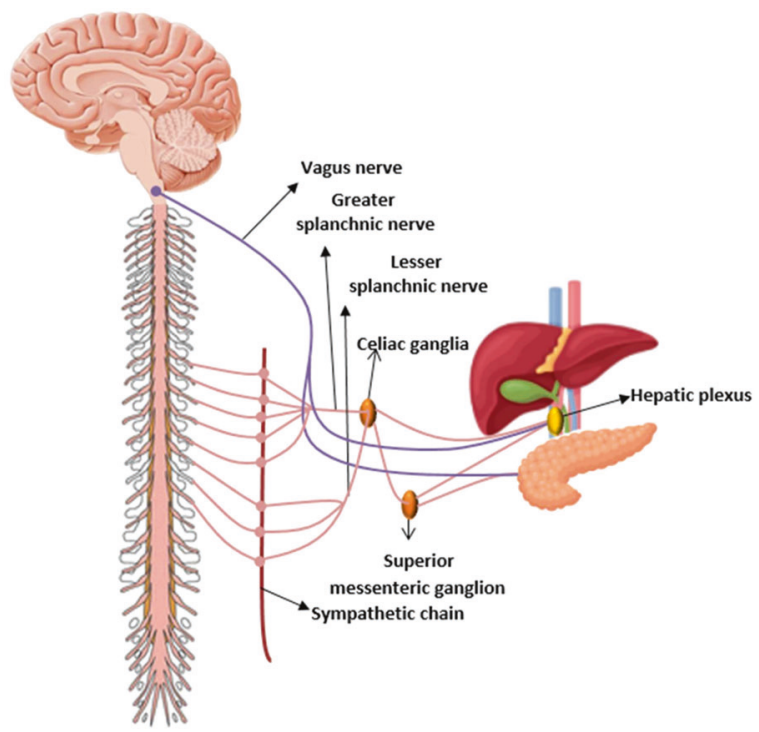

Fig. 2 A schematic overview of normal pancreas and liver innervation by the PSNS (in purple) and the SNS (in pink). SNS innervation of the liver and pancreas is derived from the lateral horn of the spinal cord (liverT7-T12, pancreas C8-L3) across through sympathetic chain primarily via the splanchnic nerve to prevertebral ganglia including the celia and superior ganglion entering hepatic plexus. The PSNS supporting the liver and pancreas originates from the brainstem (dorsal motor nucleus of the $\mathrm{n}$. vagus in the medulla) and activates parasympathetic postganglionic neurons in the liver or the pancreatic ganglia [28-31].

contact between cancer cells and nerves leads to a fertile ground for PNI. In addition, numerous signal transduction pathways, neurotransmitters, and neuropeptides regulate the pathophysiology of cancer cells [32-34]. Neurotransmitters can interact with cancer cells and in exchange the cancer cells can also release neurotransmitters which can activate receptors on nerve fibers. This stimulation possibly causes dysregulation of the nerve fiber network and acceleration of PNI [35].

\section{Norepinephrine (NE)}

$\mathrm{NE}$ is an indispensable neurotransmitter released by the postganglionic sympathetic neurons that is involved in cell migration activity [36]. The migration of tumor cells is needed for the development of cancer metastases [37]. Migration activity mediated by norepinephrine occurs via acting on $\beta-2$ adrenergic receptors and this can be influenced by using $\beta$-blockers [38]. A study in mice demonstrated that when NE is induced in development, the secretion of neurotrophins is accelerated. The inhibition of neurotrophins receptors improved the effect of gemcitabine's treatment (gemcitabine is a chemotherapy commonly used in pancreatic cancer) [39]. In CCA cell lines (MzChA-1 cells), using immunocytochemistry and immunoblotting $\alpha$-2-adrenergic receptor was stimulated by $\mathrm{NE}$, causing an upregulation of cAMP. cAMP stimulates or inhibits mitosis depending on the cell type. By prolonged EGF stimulation, by NE or cAMP, an increase of RAF-1 and B-RAF was achieved. This opens new possible therapeutic targets because the inhibition of growth occurred downstream of RAS [40]. The study demonstrated that $\beta-2$ and $\alpha-2$ adrenergic receptors were significantly downregulated in a differentiation signature involved in the above process and promote cancer progression. Thereby, p53 mutation was linked to poor survival. Deficiency of p53 can lead to cancer-associated neurogenesis with an adrenergic phenotype and a poor survival in head and neck cancer [41].

\section{Acetylcholine (Ach)}

Ach and its ligands nicotinic acetylcholine receptors (nAChRs) participate as functional neurotransmitters in the cholinergic system and they play a stimulating role in the progression of PDAC and CCA [42-44]. In CD18/HPAF pancreatic cell implantation in mice, nicotine treatment stimulated the $\alpha 7$ subunit of nicotinic acetylcholine receptor (7-nAChR) and enhanced cancer metastasis. This stimulation of 7-nAChR resulted in an activation of Janus kinase2 (JAK2)/STAT3 signaling cascade together with the protein kinase (Ras/Raf/MEK/ERK1/2) pathway [45]. Also, higher densities of muscarinic Ach receptor 3 (M3) showed an association with high-grade differentiation of PDAC, more lymph node metastasis and a shorter patient overall survival (OS) [44]. In CCA, the presence of the cholinergic system plays a role in CCA cell proliferation and growth [46, 47].

\section{Nerve growth factor (NGF)}

NGF has been extensively studied and it has been shown that NGF not only acts directly on the peripheral and central nervous system, but also on the components of the TME [48]. NGF treatment can trigger the cancer cells to stay in a more differentiated cell phenotype and thus reduce tumor growth [48, 49]. Besides the effect on the cancer cell phenotype there is a possible interaction between the immune cells in the TME. NGF is able to act on immune cell activities and this enables NGF to play an important role in the immunity against cancer. Two important cell surface receptors on neurotrophins have been described: tropomyosin receptor kinase A (TRKA) and p75 neurotrophin receptor [50-52]. In CCA patients, high levels of NGF and high levels of TRKA have been shown to be a marker for poor prognosis [53]. In PDAC, overexpression of NGF promoted pancreatic cell proliferation and invasiveness and was associated with poor prognosis of PDAC [54]. Saloman et al. injected NGF antibodies in a xenograft mouse model of PDAC. It appeared that anti-NGF treatment reduced neural inflammation, neural invasion, and metastasis in this 
model only after recent onset of the disease. This indicates that the timing of treatment would be critical [55]. Furthermore in the biliary system in rats it was shown that cholangiocytes secrete NGF and express NGF receptors. NGF promoted cholangiocyte proliferation in synergy with estrogen [56]. It has been shown in human CCA cell lines (QBC939) that NGF- $\beta$ induced progression of the disease [57]. Other studies also confirmed that the role of NGF- $\beta$ in human hilar CCA was associated with lymph node metastasis and nerve infiltration [58].

\section{Crosstalk between neural systems and cancer}

Two recent reviews reveal the importance of nerves in cancer and describe the bidirectional crosstalk of the nervous system. The nerves are able to control cancer initiation, growth and metastasis, whereas the cancer induces functional alterations of the nervous system (Fig. 3 shows an overview of the bidirectional crosstalk) [49, 59]. Nerves often travel together with blood vessels, mainly arterioles

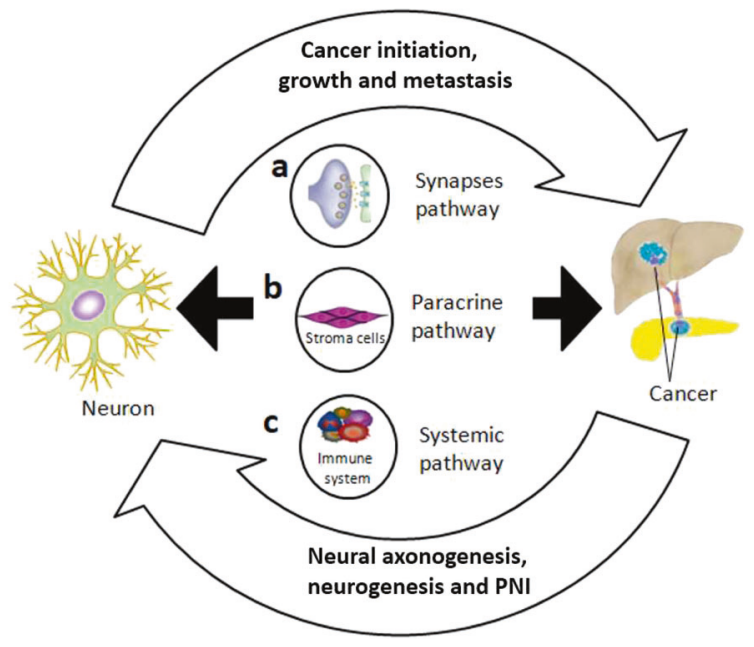

Fig. 3 A bidirectional crosstalk between nerves and cancer in pancreas and liver. Nerve fibers as branches of neuron infiltrate the TME and control cancer cells initiation, growth and metastasis mainly through three interactions pathways: a Direct contact in a synapse pathway, neuron as presynaptic cell via secretion of neurotransmitters and neuropeptides such as acetylcholin act on neurotransmitter receptors such as acetylcholin receptors on postsynaptic cell to regulate epithelial proliferation, stem cell activity, both nerve and liver or pancreatic cancer cells can be as pre- or post-synaptic cells in this communication. b Paracrine pathway, within TME, addition to direct influence, nerves communication with cancer can be mediated by regulation of tumor-related stroma cells. And the paracrine signals (neurotrophic growth factors) derived by cancer cell promote nerve axonogenesis or neurogenesis in TME. c Systemic pathway, nervous system can influence cancer cells activities through regulation the function of immune system mediated by elevated systemic circulating catecholamines. PNI can also be a consequence of circulating signals from cancer cells $[42,59]$. and capillaries, and share the same distribution [60]. In addition, adrenergic nerves can activate and initiate angiogenesis in the early stage of cancer [9]. For the tissue to make the transition from hyperplasia to neoplasia there is a need for angiogenic activity and neovascularization [61]. Evidence showed that adrenergic nerves, through the $\beta$ adrenergic receptor pathway, are important in facilitating tumor growth and cancer cell dissemination in prostate cancer $[62,63]$. Hence pharmacological blockade of adrenergic-ß-blockers can improve survival [62]. Previous work suggests that a $\beta$-blocker therapy could show lower recurrence and lower mortality in many types of cancer including PDAC [63-66]. Nerves contribute to the development of a new vascular network and they help in supplying the TME for oxygen, nutrients, and removal of waste products [9]. Neurogenesis is driven by neural progenitors in the TME which are strongly associated with tumor infiltration and dissemination [67]. An increased density of nerve fibers in the tumor lesion is correlated with high-grade disease and increased pathological stage, including for cancers of head and neck [68], breast [69], lung [70], stomach [71], prostate [26, 62], colon and rectum [72]. For PDAC it is suggested to be the other way around: a low nerve fiber density correlates with a poorer survival [73]. In another study, a high nerve fiber density of the parasympathetic nerve fibers correlated with tumor budding and a poor survival [74].

Nerve fibers from different origins have a different influence and can be indicative of a protective or aggressive role. Previous work has investigated the role of adrenergic nerves in prostate cancer, this work illustrates that the adrenergic nerve fibers are important in the "angiogenic switch", which activates endothelial cells to support exponential tumor growth [9]. Analysis of clinical outcome in 43 prostate cancer patients showed that parasympathetic nerve fibers are involved in early tumor development and the parasympathetic nerve fibers play a role in the tumor progression and more disseminated disease [62]. A retrospective study of PDAC specimens found consistent results and in PDAC the parasympathetic neurogenesis is highly associated with a poor prognosis [74]. PDAC mouse model experiments have investigated the role of nerves in the TME, multiple studies have shown that targeting the nerves in the TME could contribute to the prevention of paraneoplastic lesions to develop into cancer [75-77].

In one of these experiments, xenograft mouse models and genetically engineered mouse models of PDAC are used to investigate the role of peripheral nerves in the paraneoplastic lesion, where neonatal capsaicin is administered to ablate the sensory innervation of the pancreas. The results show that in the early stage of cancer, denervation of the pancreas slows pancreatic intraepithelial neoplasia progression and ultimately increases survival [76]. Denervation treatment has been shown to be effective in 
early stages of cancer. However, in a metastatic PDAC mouse model, mice with vagotomy (with a part of the PSNS) have an accelerated tumorigenesis. Systemic administration of a muscarinic agonist reduced this effect in the mice that underwent vagotomy [7]. These results indicate that denervation treatment combined with another therapy can be effective.

During the tumor formation process, tumor cells may attract neural progenitors which induce neurogenesis to support their growth and metastasis. Adrenergic nerve fibers and newly formed neural networks develop and infiltrate into the cancer-related stroma, providing signals to regulate tumor progression [78]. Previous studies have presented that newly formed adrenergic nerve fibers are participators involved in prostate carcinogenesis and progression and this was associated with a poor clinical outcome [9, 26, 62]. Recently it was shown that p53 mutation status in head and neck cancer was related with an adrenergic transdifferentiating of the nerves in the tumor and this was associated with a poor clinical outcome [78].

\section{Crosstalk between nerves and immune cells}

Previous literature shows that communication and interaction between the nervous system and the immune system exists. The ANS has a regulatory effect on the inflammatory response [79]. The peripheral nervous system interacts by efferent and afferent nerves which innervate primary and secondary lymphoid organs such as the spleen and lymph nodes. $\mathrm{T}$ cells originate in the thymus and then spread to peripheral organs [80]. During the process of $\mathrm{T}$ cell development and differentiation, neuro-immune communications in the thymus play a key role [81]. A current study reveals the distribution of nerve fibers in mouse thymus venules: there is a dense network of nerve fibers present in all thymic compartments. Inside the thymus, nerve fibers are closely associated with the blood vessels including postcapillary venules. This indicates that neural regulation may be involved in lymphocyte transport since $\mathrm{T}$ cell precursors and mature lymphocytes enter the peripheral organs through postcapillary venules [82]. In our own recent study, we show in our cohort of PDAC patients, that nerve fibers are co-localized with clusters of lymphocytes. These clusters are mainly CD20 positive B cells, CD4+ CD $8+T$ cells and $\mathrm{CD} 21+$ follicular dendritic cells (unpublished data).

Besides the co-localization of nerve fibers with immune cells, the patients with a high nerve fiber density show a better survival. This phenomenon is described as neuroimmune cell units (NICUs), in other studies: immune cell and nerve fiber co-localization and their interaction can drive tissue protection and can play a critical immuneregulatory role $[83,84]$. NICUs are present in many tissues around the body and are shown to be important in many physiological processes such as tissue repair, inflammation and organogenesis $[85,86]$. However, the current knowledge of NICUs is limited. In conclusion, exploring this prominent novel field in cancer research will unravel future pathways for a better response to novel therapy strategies and may make PDAC and CCA patients more primed for a better response to immunotherapy.

\section{Crosstalk between nerves and fibroblasts}

Within the TME, cancer-associated fibroblasts (CAFs) are the major stromal cell type (up to $80 \%$ of the tumor mass in PDAC). The remodeling of the stromal compartment contributes to cancer growth and progression by activation of secretion of cytokines [87, 88]. PDAC and CCA are typically characterized by a significant desmoplastic reaction. The desmoplastic stroma creates a physical and chemical barrier to prevent therapeutics and immune cells to infiltrate and reach the cancer. This results in an immune cell depleted TME and could be an explanation for failure of response to immunotherapy [89]. In addition, during the ECM remodeling, a type I collagen predominate phenotype, tends to stimulate angiogenesis and neurogenesis facilitating neo-vessel formation, which is beneficial for tumor dissemination [49]. In PDAC and CCA, CAFs are differentiated from stellate cells, these stellate cells play an essential role in the desmoplastic reaction through the expression of alpha-smooth muscle actin ( $\alpha$-SMA) and colocalization with procollagen, contributing to ECM remodeling [3]. Furthermore, stellate cells favor nerve outgrowth during tumor development by supporting growth and elongation of neurons and communicate via Ach signaling pathways [90]. A few studies have described that hepatic stellate cells regulate nerve growth via the alteration of ECM composition and up-expression of several factors such as tumor growth factor beta, which stimulates angiogenesis and with this influences axons in the TME [91]. Abundant ECM components such as hyaluronic acid, fibronectin and collagen are predominately present within the TME in PDAC and CCA. Those ECM components influence neuron growth $[92,93]$. Hence, stellate cells regulate the composition of ECM components and therefore affect nerve growth in PDAC and CCA [90].

CAFs can secrete matrix metalloproteases (MMPs), the MMP family is an ECM protein and they are reported to be regulators of neural development [94]. It was described that some MMPs (MT1-MMP) are shown to degrade the ECM and promote pancreatic cancer expansion, invasion, and progression to an advanced stage $[95,96]$. It is reported that MMP9 is associated with more lymph node metastasis and a poorer survival in breast cancer [97]. PDAC cells in vivo 
Table 1 Summary of current research neural remodeling in PDAC and CCA.

\begin{tabular}{|c|c|c|c|c|}
\hline References & Samples & Neural marker & Key results & Cancer types \\
\hline Iwasaki et al. [73] & 256 & GAP-43 & Neural hypertrophy and nerve numbers are decreased; & Pancreatic carcinoma \\
\hline Fisher et al. [105] & 58 & & Presence of PNI was associated with a reduction of OS & Cholangiocarcinoma \\
\hline $\begin{array}{l}\text { Chatterjee et al. } \\
{[17]}\end{array}$ & 212 & & $\begin{array}{l}\text { Presence of PNI was directly correlated with tumor size, margin status, } \\
\text { lymph node metastasis, pathologic tumor and AJCC stages, and shorter } \\
\text { DFS and OS }\end{array}$ & $\begin{array}{l}\text { Pancreatic } \\
\text { carcinoma }\end{array}$ \\
\hline Lenz et al. [106] & 177 & & $\begin{array}{l}80.3 \% \text { of PDAC detected PNI; Neural remodeling progress can be a reason } \\
\text { of pancreatic neuropathy; }\end{array}$ & $\begin{array}{l}\text { Pancreatic } \\
\text { carcinoma }\end{array}$ \\
\hline $\begin{array}{l}\text { Shimada et al. } \\
\text { [99] }\end{array}$ & 153 & & $\begin{array}{l}\text { Degree of PNI was directly related to lymph node metastases, surgical } \\
\text { margin and tumor sides size, and inversely associated with DFS }\end{array}$ & $\begin{array}{l}\text { Pancreatic } \\
\text { carcinoma }\end{array}$ \\
\hline $\begin{array}{l}\text { Ceyhan et al. } \\
\text { [107] }\end{array}$ & 97 & $\begin{array}{l}\text { GAP-43 } \\
\text { NGF } \\
\text { PGP9.5 } \\
\text { Artemin }\end{array}$ & $\begin{array}{l}\text { There were enlarged nerves and dense neural networks in pancreatic } \\
\text { carcinoma slides; } \\
\text { Neurotrophic characteristics GAP- } 43 \text {, NGF and Artemin are increased in } \\
\text { pancreatic carcinoma and have close relevancy with intrapancreatic } \\
\text { neuropathy. }\end{array}$ & $\begin{array}{l}\text { Pancreatic } \\
\text { carcinoma }\end{array}$ \\
\hline $\begin{array}{l}\text { Ceyhan et al. } \\
{[103]}\end{array}$ & 149 & $\begin{array}{l}\text { GAP-43 } \\
\text { PGP9.5 } \\
\text { NGF }\end{array}$ & $\begin{array}{l}\text { Neural hypertrophy, neural density increased; } \\
\text { Neuropathic alteration was not correlated with survival in pancreatic } \\
\text { carcinoma, these changes include neural thickness, hypertrophy, density. } \\
\text { Only the severity of pain significantly affects survival. }\end{array}$ & $\begin{array}{l}\text { Pancreatic } \\
\text { carcinoma }\end{array}$ \\
\hline $\begin{array}{l}\text { Ceyhan et al. } \\
\text { [103] }\end{array}$ & 564 & GAP-43 & $\begin{array}{l}\text { Neural density is increased and nerves are enlarged in pancreatic } \\
\text { carcinoma, the severity of PNI was linked to neuropathic changes and pain. }\end{array}$ & $\begin{array}{l}\text { Pancreatic } \\
\text { carcinoma }\end{array}$ \\
\hline Shirai et al. [104] & 59 & & $\begin{array}{l}80 \% \text { of CCA samples detected PNI; } \\
5 \text { years survival rates of patients with or without PNI were } 17 \% \text { and } 70 \% \text {, } \\
\text { respectively. }\end{array}$ & Cholangiocarcinoma \\
\hline
\end{tabular}

undergoing chronic stress, were sensitive to neural signaling and pancreatic stromal cells were increased. This promoted tumor metastasis and cancer progression, $\beta$-adrenergic receptor blockade intervention therapy can block this neural signaling and be part of a combination therapy for PDAC [63].

\section{Pathological features of nerve fibers in PDAC and CCA}

PNI is considered as an important factor for poor prognosis in PDAC and CCA [24, 98]. It has been shown that PNI can be the reason for curative resection failure (shown in Table 1). Chatterjee et al. showed by examination of 212 PDAC slides, that the presence of PNI was directly correlated with tumor size, margin status, lymph node metastasis, and AJCC stages and inversely associated with disease free survival (DFS) and OS [17]. Shimada et al. found that the degree of intrapancreatic nerve invasion can be used as a predictor for recurrence of disease after surgery [99]. A phenomenon termed as "neural remodeling" is postulated in PDAC, characterized by the alterations in morphology of the nerve $[18,100-102]$. It was shown that nerve fiber alterations including hypertrophic nerves, increased nerve fiber density and pancreatic neuritis were strongly associated with GAP-43 overexpression and abdominal pain [103]. In the perineural space, PNI induces reactive alterations in the morphology and function of the nerves. Morphological changes include changes of the nerve trunk and thickness [102]. The aggressiveness of PNI is related to neural remodeling, desmoplasia and cancer pain. Severe and enduring pain was strongly associated with poor survival in PDAC patients. However, these neural alterations did not have a significant association with survival [103]. NGF and Artemin play a fundamental role in neural modeling in pancreatic adenocarcinoma.

Interestingly, lower intrapancreatic neural density in the tumor area was linked to shorter OS with multivariate analysis [73]. Related research in CCA mainly focused on PNI prevalence and patient survival [45, 99, 104]. In summary, these studies consistently showed that the presence of PNI was linked to shorter survival in patients with PDAC or CCA. The significance that PNI is an independent prognostic factor of poor outcome has been demonstrated. However, the influence of nerve remodeling especially the new outgrown small nerve fibers has not been fully explained.

\section{Conclusions and future directions}

With its frequent PNI, PDAC and CCA are two neurotropic cancers. The neurotropism of these cancers could be an explanation of their aggressiveness and poor response to treatment. In this review, the progress of recent research in 
the mechanism of PNI in PDAC and CCA is discussed. However, the crosstalk between the nervous system in PDAC and CCA is undiscovered. Different nerve fibers have a different function and the interaction with the components of the TME and the cancer are important to investigate.

In PDAC, the role of nerve fibers is divergent and nerves from the PSNS and SNS have a cancer stimulating and cancer inhibiting effect. To our current knowledge, detailed understanding of the underlying mechanisms of tumor and nerve fiber interaction is critical for the development of innovative therapeutic strategies for patients with these highly lethal cancers. The nerve outgrowth is part of the TME, in which cancer to stroma crosstalk takes place. It is likely that other components of the TME also influence the nerve outgrowth and immune cells and fibroblasts are key components in this process. Targeting nerves has the potential to be a new strategy for therapy for PDAC and CCA patients by influencing the TME, immune cells and fibroblasts, potentially influencing sensitivity to therapeutics. The newly formed nerve fibers are different from the more commonly used PNI. From our perspective, PNI originates in the pre-existing nerve fiber networks and the cancer uses the distribution network for cancer growth. This is a well-known sign of aggressive disease and is associated with poor survival. Small nerve fiber outgrowth can be used as a biomarker for a better survival, as a tool to stratify patients for treatment and as a target for therapeutics. More research is needed to investigate whether sensitivity to already existing immunotherapy can be achieved by targeting nerves.

Acknowledgements X. Tan was funded by China Scholarship Council (Grantnumber: 201806210074). Open Access funding enabled and organized by Projekt DEAL.

\section{Compliance with ethical standards}

Conflict of interest JdeV-G has served as a consultant for AstraZeneca, MSD, and Servier, and has received institutional research funding from Servier. All outside the submitted work.

Publisher's note Springer Nature remains neutral with regard to jurisdictional claims in published maps and institutional affiliations.

Open Access This article is licensed under a Creative Commons Attribution 4.0 International License, which permits use, sharing, adaptation, distribution and reproduction in any medium or format, as long as you give appropriate credit to the original author(s) and the source, provide a link to the Creative Commons license, and indicate if changes were made. The images or other third party material in this article are included in the article's Creative Commons license, unless indicated otherwise in a credit line to the material. If material is not included in the article's Creative Commons license and your intended use is not permitted by statutory regulation or exceeds the permitted use, you will need to obtain permission directly from the copyright holder. To view a copy of this license, visit http://creativecommons. org/licenses/by/4.0/.

\section{References}

1. Rahib L, Smith BD, Aizenberg R, Rosenzweig AB, Fleshman JM, Matrisian LM. Projecting cancer incidence and deaths to 2030: the unexpected burden of thyroid, liver, and pancreas cancers in the United States. Cancer Res. 2014;74:2913-21.

2. Bertuccio P, Malvezzi M, Carioli G, Hashim D, Boffetta P, ElSerag HB, et al. Global trends in mortality from intrahepatic and extrahepatic cholangiocarcinoma. J Hepatol. 2019;71:104-14.

3. Liu H, Ma Q, Xu Q, Lei J, Li X, Wang Z, et al. Therapeutic potential of perineural invasion, hypoxia and desmoplasia in pancreatic cancer. Curr Pharm Des. 2012;18:2395-403.

4. Maisonneuve P. Epidemiology and burden of pancreatic cancer. La Presse Médicale. 2019;48:e113-e23.

5. Khan SA, Tavolari S, Brandi G. Cholangiocarcinoma: epidemiology and risk factors. Liver Int. 2019;39:19-31.

6. McClements S, Khan SA. Epidemiology and pathogenesis of cholangiocarcinoma. In: Cross T, Palmer DH, editors. Liver cancers: from mechanisms to management. Cham: Springer International Publishing; 2019. p. 179-86.

7. Renz BW, Tanaka T, Sunagawa M, Takahashi R, Jiang Z, Macchini M, et al. Cholinergic signaling via muscarinic receptors directly and indirectly suppresses pancreatic tumorigenesis and cancer stemness. Cancer Discov. 2018;8:1458-73.

8. Farrow B, Albo D, Berger DH. The role of the tumor microenvironment in the progression of pancreatic cancer. J Surgical Res. 2008;149:319-28.

9. Zahalka AH, Arnal-Estapé A, Maryanovich M, Nakahara F, Cruz CD, Finley LWS, et al. Adrenergic nerves activate an angio-metabolic switch in prostate cancer. Science. 2017;358:321-6.

10. Hondermarck H, Jobling P. The sympathetic nervous system drives tumor angiogenesis. Trends Cancer 2018;4:93-4.

11. March B, Faulkner S, Jobling P, Steigler A, Blatt A, Denham J, et al. Tumour innervation and neurosignalling in prostate cancer. Nat Rev Urol. 2020;17:119-30.

12. Bapat AA, Galen H, Hoff DD, Von, Haiyong H. Perineural invasion and associated pain in pancreatic cancer. Nat Rev Cancer. 2011;11:695.

13. Bockman DE, Büchler M, Beger HG. Interaction of pancreatic ductal carcinoma with nerves leads to nerve damage. Gastroenterology. 1994;107:219-30.

14. Liebig C, Ayala G, Wilks JA, Berger DH, Albo D. Perineural invasion in cancer: a review of the literature. Cancer. 2009;115:3379-91.

15. Batsakis JG. Nerves and neurotropic carcinomas. Ann Otol Rhinol Laryngol. 1985;94:426-7.

16. Gasparini G, Pellegatta M, Crippa S, Lena MS, Belfiori G, Doglioni $\mathrm{C}$, et al. Nerves and pancreatic cancer: new insights into a dangerous relationship. Cancers. 2019;11:893.

17. Chatterjee D, Katz MH, Rashid A, Wang H, Iuga AC, Varadhachary GR, et al. Perineural and intraneural invasion in posttherapy pancreaticoduodenectomy specimens predicts poor prognosis in patients with pancreatic ductal adenocarcinoma. Am J Surg Pathol. 2012;36:409-17.

18. Demir IE, Ceyhan GO, Liebl F, D’Haese JG, Maak M, Friess H. Neural invasion in pancreatic cancer: the past, present and future. Cancers. 2010;2:1513-27.

19. Shen F-Z, Zhang B-Y, Feng Y-J, Jia Z-X, An B, Liu C-C, et al. Current research in perineural invasion of cholangiocarcinoma. $J$ Exp Clin Cancer Res. 2010;29:24.

20. Liang D, Shi S, Xu J, Zhang B, Qin Y, Ji S, et al. New insights into perineural invasion of pancreatic cancer: more than pain. Biochimica et Biophysica Acta (BBA)-reviews on. Cancer. 2016;1865:111-22. 
21. Pundavela J, Roselli S, Faulkner S, Attia J, Scott RJ, Thorne RF, et al. Nerve fibers infiltrate the tumor microenvironment and are associated with nerve growth factor production and lymph node invasion in breast cancer. Mol Oncol. 2015;9:1626-35.

22. Zareba P, Flavin R, Isikbay M, Rider JR, Gerke TA, Finn S, et al. Perineural invasion and risk of lethal prostate cancer. Cancer Epidemiol Biomark Prev. 2017;26:719-26.

23. Chen S-H, Zhang B-Y, Zhou B, Zhu C-Z, Sun L-Q, Feng Y-J. Perineural invasion of cancer: a complex crosstalk between cells and molecules in the perineural niche. Am J Cancer Res. 2019;9:1-21.

24. Ren K, Yi SQ, Dai Y, Kurosawa K, Miwa Y, Sato I. Clinical anatomy of the anterior and posterior hepatic plexuses, including relations with the pancreatic plexus: a cadaver study. Clin Anat. 2020;33:630-6.

25. Mavros MN, Economopoulos KP, Alexiou VG, Pawlik TM. Treatment and prognosis for patients with intrahepatic cholangiocarcinoma: systematic review and meta-analysis. JAMA Surg. 2014;149:565-74.

26. Ayala GE, Dai H, Powell M, Li R, Ding Y, Wheeler TM, et al. Cancer-related axonogenesis and neurogenesis in prostate cancer. Clin Cancer Res. 2008;14:7593-603.

27. Zuo H-D, Zhang X-M, Li C-J, Cai C-P, Zhao Q-H, Xie X-G, et al. CT and MR imaging patterns for pancreatic carcinoma invading the extrapancreatic neural plexus (Part I): anatomy, imaging of the extrapancreatic nerve. World $\mathrm{J}$ Radiol. 2012;4:36-43.

28. Li W, Yu G, Liu Y, Sha L. Intrapancreatic ganglia and neural regulation of pancreatic endocrine secretion. Front Neurosci. 2019;13:21.

29. Mizuno K, Ueno Y. Autonomic nervous system and the liver. Hepatol Res. 2017;47:160-5.

30. Rodriguez-Diaz R, Caicedo A. Neural control of the endocrine pancreas. Best Pr Res Clin Endocrinol Metab. 2014;28:745-56.

31. Babic T, Alberto TR. Neural control of the pancreas. Panc. 2016;27. https://doi.org/10.3998/panc.2016.27.

32. Franchitto A, Onori P, Renzi A, Carpino G, Mancinelli R, Alvaro D, et al. Recent advances on the mechanisms regulating cholangiocyte proliferation and the significance of the neuroendocrine regulation of cholangiocyte pathophysiology. Ann Transl Med. 2013;1:27.

33. Sha M, Cao J, Sun H-y, Tong Y, Xia Q. Neuroendocrine regulation of cholangiocarcinoma: a status quo review. Biochim Biophys Acta. 2019;1872:66-73.

34. Dang N, Meng X, Song H. Nicotinic acetylcholine receptors and cancer. Biomed Rep. 2016;4:515-8.

35. Liu H-P, Tay S-S-W, Leong S-K, Schemann M. Colocalization of ChAT, D $\beta \mathrm{H}$ and NADPH-d in the pancreatic neurons of the newborn guinea pig. Cell Tissue Res. 1998;294:227-31.

36. O'Donnell J, Zeppenfeld D, McConnell E, Pena S, Nedergaard M. Norepinephrine: a neuromodulator that boosts the function of multiple cell types to optimize CNS performance. Neurochem Res. 2012;37:2496-512.

37. Campbell K, Rossi F, Adams J, Pitsidianaki I, Barriga FM, Garcia-Gerique L, et al. Collective cell migration and metastases induced by an epithelial-to-mesenchymal transition in Drosophila intestinal tumors. Nat Commun. 2019;10:2311.

38. Barbieri A, Bimonte S, Palma G, Luciano A, Rea D, Giudice A, et al. The stress hormone norepinephrine increases migration of prostate cancer cells in vitro and in vivo. Int $\mathrm{J}$ Oncol. 2015;47:527-34.

39. Renz BW, Takahashi R, Tanaka T, Macchini M, Hayakawa Y, Dantes $\mathrm{Z}$, et al. $\beta 2$ adrenergic-neurotrophin feedforward loop promotes pancreatic cancer. Cancer Cell. 2018;33:75-90.e7.

40. Kanno N, LeSage G, Phinizy JL, Glaser S, Francis H, Alpini G. Stimulation of $\alpha 2$-adrenergic receptor inhibits cholangiocarcinoma growth through modulation of Raf-1 and B-Raf activities. Hepatology. 2002;35:1329-40.

41. Amit M, Takahashi H, Dragomir MP, Lindemann A, GleberNetto FO, Pickering CR, et al. Loss of p53 drives neuron reprogramming in head and neck cancer. Nature. 2020;578: 449-54.

42. Jobling P, Pundavela J, Oliveira SM, Roselli S, Walker MM, Hondermarck H. Nerve-cancer cell cross-talk: a novel promoter of tumor progression. Cancer Res. 2015;75:1777-81.

43. Feng Y-J, Zhang B-Y, Yao R-Y, Lu Y. Muscarinic acetylcholine receptor $\mathrm{M} 3$ in proliferation and perineural invasion of cholangiocarcinoma cells. Hepatobiliary Pancreat Dis Int. 2012;11: 418-23.

44. Zhang L, Xiu D, Zhan J, He X, Guo L, Wang J, et al. High expression of muscarinic acetylcholine receptor 3 predicts poor prognosis in patients with pancreatic ductal adenocarcinoma. Onco Targets Ther. 2016;9:6719-26.

45. Momi N, Ponnusamy MP, Kaur S, Rachagani S, Kunigal SS, Chellappan S, et al. Nicotine/cigarette smoke promotes metastasis of pancreatic cancer through alpha7nAChR-mediated MUC4 upregulation. Oncogene 2013;32:1384-95.

46. Amonyingcharoen S, Suriyo T, Thiantanawat A, Watcharasit P, Satayavivad J. Taurolithocholic acid promotes intrahepatic cholangiocarcinoma cell growth via muscarinic acetylcholine receptor and EGFR/ERK1/2 signaling pathway. Int J Oncol. 2015;46:2317-26.

47. Martínez AK, Jensen K, Hall C, O’Brien A, Ehrlich L, White T, et al. Nicotine promotes cholangiocarcinoma growth in xenograft mice. Am J Pathol. 2017;187:1093-105.

48. Aloe L, Rocco ML, Balzamino BO, Micera A. Nerve growth factor: role in growth, differentiation and controlling cancer cell development. J Exp Clin Cancer Res. 2016;35:116.

49. Zahalka AH, Frenette PS. Nerves in cancer. Nat Rev Cancer. 2020;20:143-57.

50. Roux PP, Barker PA. Neurotrophin signaling through the p75 neurotrophin receptor. Prog Neurobiol. 2002;67:203-33.

51. Schecterson LC, Bothwell M. Neurotrophin receptors: old friends with new partners. Dev Neurobiol. 2010;70:332-8.

52. Molloy NH, Read DE, Gorman AM. Nerve growth factor in cancer cell death and survival. Cancers. 2011;3:510-30.

53. Yang XQ, Xu YF, Guo S, Liu Y, Ning SL, Lu XF, et al. Clinical significance of nerve growth factor and tropomyosin-receptorkinase signaling pathway in intrahepatic cholangiocarcinoma. World J Gastroenterol. 2014;20:4076-84.

54. Ma J, Jiang Y, Jiang Y, Sun Y, Zhao X. Expression of nerve growth factor and tyrosine kinase receptor $\mathrm{A}$ and correlation with perineural invasion in pancreatic cancer. J Gastroenterol Hepatol. 2008;23:1852-9.

55. Saloman JL, Singhi AD, Hartman DJ, Normolle DP, Albers KM, Davis BM. Systemic depletion of nerve growth factor inhibits disease progression in a genetically engineered model of pancreatic ductal adenocarcinoma. Pancreas. 2018;47:856-63.

56. Gigliozzi A, Alpini G, Baroni GS, Marucci L, Metalli VD, Glaser SS, et al. Nerve growth factor modulates the proliferative capacity of the intrahepatic biliary epithelium in experimental cholestasis. Gastroenterology. 2004;127:1198-209.

57. Yue XJ, Xu LB, Zhu MS, Zhang R, Liu C. Over-expression of nerve growth factor-beta in human cholangiocarcinoma QBC939 cells promote tumor progression. PloS One. 2013;8:e62024.

58. Xu LB, Liu C, Gao GQ, Yu XH, Zhang R, Wang J. Nerve growth factor-beta expression is associated with lymph node metastasis and nerve infiltration in human hilar cholangiocarcinoma. World J Surg. 2010;34:1039-45.

59. Monje M, Borniger JC, D’Silva NJ, Deneen B, Dirks PB, Fattahi F, et al. Roadmap for the emerging field of cancer neuroscience. Cell. 2020;181:219-22. 
60. Eichmann A, Brunet I. Arterial innervation in development and disease. Sci Transl Med. 2014;6:252ps9-ps9.

61. Folkman J, Watson K, Ingber D, Hanahan D. Induction of angiogenesis during the transition from hyperplasia to neoplasia. Nature. 1989;339:58-61.

62. Magnon C, Hall SJ, Lin J, Xue X, Gerber L, Freedland SJ, et al. Autonomic nerve development contributes to prostate cancer progression. Science. 2013;341:713-4.

63. Kim-Fuchs C, Le CP, Pimentel MA, Shackleford D, Ferrari D, Angst E, et al. Chronic stress accelerates pancreatic cancer growth and invasion: a critical role for beta-adrenergic signaling in the pancreatic microenvironment. Brain Behav Immun. 2014;40:40-7.

64. Kamiya A, Hayama Y, Kato S, Shimomura A, Shimomura T, Irie $\mathrm{K}$, et al. Genetic manipulation of autonomic nerve fiber innervation and activity and its effect on breast cancer progression. Nat Neurosci. 2019;22:1289-305.

65. Barron TI, Connolly RM, Sharp L, Bennett K, Visvanathan K. Beta blockers and breast cancer mortality: a population-based study. J Clin Oncol. 2011;29:2635-44.

66. Grytli HH, Fagerland MW, Fossa SD, Tasken KA. Association between use of beta-blockers and prostate cancer-specific survival: a cohort study of 3561 prostate cancer patients with highrisk or metastatic disease. Eur Urol. 2014;65:635-41.

67. Mauffrey P, Tchitchek N, Barroca V, Bemelmans A-P, Firlej V, Allory Y, et al. Progenitors from the central nervous system drive neurogenesis in cancer. Nature. 2019;569:672-8.

68. Raju B, Haug SR, Ibrahim SO, Heyeraas KJ. Sympathectomy decreases size and invasiveness of tongue cancer in rats. Neuroscience. 2007;149:715-25.

69. Huang D, Su S, Cui X, Shen X, Zeng Y, Wu W, et al. Nerve fibers in breast cancer tissues indicate aggressive tumor progression. Medicine. 2014;93:e172.

70. Shao JX, Wang B, Yao YN, Pan ZJ, Shen Q, Zhou JY. Autonomic nervous infiltration positively correlates with pathological risk grading and poor prognosis in patients with lung adenocarcinoma. Thorac Cancer. 2016;7:588-98.

71. Zhao CM, Hayakawa Y, Kodama Y, Muthupalani S, Westphalen CB, Andersen GT, et al. Denervation suppresses gastric tumorigenesis. Sci Transl Med. 2014;6:250ra115.

72. Albo D, Akay CL, Marshall CL, Wilks JA, Verstovsek G, Liu H, et al. Neurogenesis in colorectal cancer is a marker of aggressive tumor behavior and poor outcomes. Cancer. 2011;117:4834-45.

73. Iwasaki T, Hiraoka N, Ino Y, Nakajima K, Kishi Y, Nara S, et al. Reduction of intrapancreatic neural density in cancer tissue predicts poorer outcome in pancreatic ductal carcinoma. Cancer Sci. 2019;110:1491-502.

74. Zhang L, Guo L, Tao M, Fu W, Xiu D. Parasympathetic neurogenesis is strongly associated with tumor budding and correlates with an adverse prognosis in pancreatic ductal adenocarcinoma. Chin J Cancer Res. 2016;28:180-6.

75. Sinha S, Fu YY, Grimont A, Ketcham M, Lafaro K, Saglimbeni JA, et al. PanIN neuroendocrine cells promote tumorigenesis via neuronal cross-talk. Cancer Res. 2017;77:1868-79.

76. Saloman JL, Albers KM, Li D, Hartman DJ, Crawford HC, Muha EA, et al. Ablation of sensory neurons in a genetic model of pancreatic ductal adenocarcinoma slows initiation and progression of cancer. Proc Natl Acad Sci USA. 2016;113:3078-83.

77. Bai H, Li H, Zhang W, Matkowskyj KA, Liao J, Srivastava SK, et al. Inhibition of chronic pancreatitis and pancreatic intraepithelial neoplasia (PanIN) by capsaicin in LSL-KrasG12D/ Pdx1-Cre mice. Carcinogenesis 2011;32:1689-96.

78. Amit M, Takahashi H, Dragomir MP, Lindemann A, Gleber-Netto FO, Pickering CR. et al. Loss of p53 drives neuron reprogramming in head and neck cancer. Nature. 2020;578:449-54.
79. Soto-Tinoco E, Guerrero-Vargas NN, Buijs RM. Interaction between the hypothalamus and the immune system. Exp Physiol. 2016;101:1463-71.

80. Thome JJ, Bickham KL, Ohmura Y, Kubota M, Matsuoka N, Gordon $\mathrm{C}$, et al. Early-life compartmentalization of human $\mathrm{T}$ cell differentiation and regulatory function in mucosal and lymphoid tissues. Nat Med. 2016;22:72-7.

81. Mignini F, Sabbatini M, Mattioli L, Cosenza M, Artico M. Neuro-immune modulation of the thymus microenvironment (Review). Int J Mol Med. 2014;33:1392-400.

82. Al-Shalan HAM, Hu D, Nicholls PK, Greene WK, Ma B. Immunofluorescent characterization of innervation and nerveimmune cell neighborhood in mouse thymus. Cell Tissue Res. 2019;378:239-54.

83. Veiga-Fernandes H, Pachnis V. Neuroimmune regulation during intestinal development and homeostasis. Nat Immunol. 2017;18:116-22.

84. Godinho-Silva C, Cardoso F, Veiga-Fernandes H. Neuroimmune cell units: a new paradigm in physiology. Annu Rev Immunol. 2019;37:19-46.

85. Veiga-Fernandes H, Mucida D. Neuro-immune interactions at barrier surfaces. Cell 2016;165:801-11.

86. Chesne J, Cardoso V, Veiga-Fernandes H. Neuro-immune regulation of mucosal physiology. Mucosal Immunol. 2019;12:10-20.

87. Cirri P, Chiarugi P. Cancer associated fibroblasts: the dark side of the coin. Am J Cancer Res. 2011;1:482-97.

88. Yu M, Tannock IF. Targeting tumor architecture to favor drug penetration: a new weapon to combat chemoresistance in pancreatic cancer? Cancer Cell. 2012;21:327-9.

89. Joyce JA, Fearon DT. T cell exclusion, immune privilege, and the tumor microenvironment. Science. 2015;348:74-80.

90. Apte MV, Wilson JS, Lugea A, Pandol SJ. A starring role for stellate cells in the pancreatic cancer microenvironment. Gastroenterology. 2013;144:1210-9.

91. Coulouarn C, Clément B. Stellate cells and the development of liver cancer: therapeutic potential of targeting the stroma. J Hepatol. 2014;60:1306-9.

92. Gritsenko PG, Ilina O, Friedl P. Interstitial guidance of cancer invasion. J Pathol. 2012;226:185-99.

93. Preston M, Sherman LS. Neural stem cell niches: roles for the hyaluronan-based extracellular matrix. Front Biosci. 2011;3: 1165-79.

94. Ulrich R, Gerhauser I, Seeliger F, Baumgartner W, Alldinger S. Matrix metalloproteinases and their inhibitors in the developing mouse brain and spinal cord: a reverse transcription quantitative polymerase chain reaction study. Dev Neurosci. 2005;27:408-18.

95. Maatta M, Soini Y, Liakka A, Autio-Harmainen H. Differential expression of matrix metalloproteinase (MMP)-2, MMP-9, and membrane type 1-MMP in hepatocellular and pancreatic adenocarcinoma: implications for tumor progression and clinical prognosis. Clin Cancer Res. 2000;6:2726-34.

96. Liu T, Zhou L, Li D, Andl T, Zhang Y. Cancer-associated fibroblasts build and secure the tumor microenvironment. Front Cell Dev Biol. 2019;7:60.

97. Roy R, Yang J, Moses MA. Matrix metalloproteinases as novel biomarkers and potential therapeutic targets in human cancer. $\mathrm{J}$ Clin Oncol. 2009;27:5287-97.

98. Yamada Y, Mori H, Hijiya N, Matsumoto S, Takaji R, Kiyonaga $\mathrm{M}$, et al. Extrahepatic bile duct cancer: invasion of the posterior hepatic plexuses-evaluation using multidetector CT. Radiology. 2012;263:419-28.

99. Shimada K, Nara S, Esaki M, Sakamoto Y, Kosuge T, Hiraoka $\mathrm{N}$. Intrapancreatic nerve invasion as a predictor for recurrence after pancreaticoduodenectomy in patients with invasive ductal carcinoma of the pancreas. Pancreas. 2011;40:464-8. 
100. Nakao A, Harada A, Nonami T, Kaneko T, Takagi H. Clinical significance of carcinoma invasion of the extrapancreatic nerve plexus in pancreatic cancer. Pancreas. 1996;12:357-61.

101. Liu B, Lu KY. Neural invasion in pancreatic carcinoma. Hepatobiliary Pancreat Dis INT. 2002;1:469-76.

102. Demir IE, Friess H, Ceyhan GO. Neural plasticity in pancreatitis and pancreatic cancer. Nat Rev Gastroenterol Hepatol. 2015;12: 649-59.

103. Ceyhan GO, Bergmann F, Kadihasanoglu M, Altintas B, Demir IE, Hinz U, et al. Pancreatic neuropathy and neuropathic pain-a comprehensive pathomorphological study of 546 cases. Gastroenterology. 2009;136:177-86.e1.

104. Shirai K, Ebata T, Oda K, Nishio H, Nagasaka T, Nimura Y, et al. Perineural invasion is a prognostic factor in intrahepatic cholangiocarcinoma. World J Surg. 2008;32:2395-402.
105. Fisher SB, Patel SH, Kooby DA, Weber S, Bloomston M, Cho $\mathrm{C}$, et al. Lymphovascular and perineural invasion as selection criteria for adjuvant therapy in intrahepatic cholangiocarcinoma: a multi-institution analysis. HPB (Oxford). 2012;14:514-22. https://doi.org/10.1111/j.1477-2574.2012.00489.x.

106. Lenz J, Karasek P, Jarkovsky J, Muckova K, Dite P, Kala Z, et al. Clinicopathological correlations of nestin expression in surgically resectable pancreatic cancer including an analysis of perineural invasion. J Gastrointestin Liver Dis. 2011;20: 389-96.

107. Ceyhan GO, Schäfer K-H, Kerscher AG, Rauch U, Demir IE, Kadihasanoglu M, et al. Nerve growth factor and artemin are paracrine mediators of pancreatic neuropathy in pancreatic adenocarcinoma. Ann Surg. 2010;251:923-31. https://doi.org/10. 1097/SLA.0b013e3181d974d4. 